\title{
LUZ ELÉTRICA EM CAMPINA GRANDE: MELHORAMENTO URBANO NA TEIA DOS JORNALISTAS E CRONISTAS
}

\section{Cataline Alves Brandão ${ }^{1}$}

\section{Resumo}

A recepção da luz elétrica na cidade de Campina Grande nas décadas de 1920 e 1940 causou na sociedade impressões das mais diversas. Nesse sentido, desde a sua inauguração, a luz elétrica em Campina Grande se mostrou precária e oscilante, trazendo a insatisfação daqueles que desejavam o "progresso" e "civilização" da cidade. A partir de uma análise atenta das fontes, sobretudo, os jornais que circulavam na cidade no período em estudo, foi possível perceber os limites deste equipamento de conforto na cidade, variadas foram às vezes em que cronistas, jornalistas e políticos trataram do que se chamou à época "o caso da luz", como um símbolo de atraso no que diz respeito à trajetória da cidade nos padrões da modernidade.

\section{Palavras-chave}

Luz elétrica- Modernidade- Campina Grande.

\section{Abstract}

The reception of the electric light in the city of Campina Grande in the 1920s and 1940s had on society in many different impressions. Accordingly, since its inauguration, the electric light in Campina Grande proved precarious and swinging, bringing the dissatisfaction of those who wanted to "progress" and "civilization" of the city. From a careful analysis of the sources, mainly newspapers circulating in the city during the study period, it was possible to realize the limits of comfort equipment in the city, were sometimes varied in which writers, journalists and politicians addressed the so-called at the time "the case of light," as a symbol of backwardness in relation to the trajectory of the city in the patterns of modernity.

\section{Keywords}

Electric light-Modernity-Campina Grande.

\footnotetext{
${ }^{1}$ Bacharel e licenciada em História pela Universidade de Campina Grande- UFCG. Mestranda do Programa de Pós- Graduação em História- UFCG, vinculada a linha de pesquisa Cultura e Cidades.
} 
Luz é claridade. Luz é sol. Luz é irradiação. Luz é refulgência. Luz é vida. Parafraseando o imenso Rui Barbosa, luz é ainda progresso. Luz é método. Luz é celeridade, luz é justiça. (Cristino Pimentel)

As cidades, na modernidade, vêm sendo há algum tempo objeto de estudo entre os historiadores, os quais buscam enfatizar as dinâmicas dessas cidades, destacando as suas modificações físicas e estruturais, bem como os impactos causados nos homens urbanos ao se depararem com a avalanche de modificações sentidas na modernidade. A experiência moderna revela relações impactantes, marcadas por mudanças e eventos inesperados.

Nesse percurso vislumbrado nas cidades devemos considerar as reações que as modificações urbanas vão causar na sociedade. Assim, os jornais passam a ser veículos fundamentais da transmissão das informações

acerca das mudanças cotidianas, trazendo o desejo pelo novo, as limitações de determinados aparatos modernos, assim como a luta pela permanência da tradição.

Brescianni (1997) considera as cidades como sendo uma experiência visual, marcada pela organização dos traçados das ruas, das grandes artérias e das vias de circulação de pessoas, as amplas construções arquitetônicas compõem este universo rico em significações e experiências sociais. A cidade moderna é, sobretudo, vista na sua materialidade, atentando para as representações construídas em torno da vida urbana e suas implicações no campo do sensível.

Tratar ainda da modernização é perceber o novo traçado de ruas e avenidas, grandes empreendimentos que trazem para o espaço urbano a possibilidade de melhorias no cotidiano, dando ares de progresso e civilização. A modernização desta maneira permite o surgimento de novas tecnologias, inovações para promover o conforto no espaço urbano.

É importante frisar a impressão causada nos intelectuais que buscaram compreender os efeitos dessa nova configuração do urbano, refletindo sobre as permanências e as mudanças nas cidades. Nesse sentido, é fundamental lembrarmos quando em referência à cidade e à modernidade, George Simmel (1979) elaborou um estudo bastante característico dos efeitos do ritmo frenético das grandes metrópoles associando seus traços ao sistema nervoso de seus habitantes. Assim, a individualidade construída pelas metrópoles se configurava no resultado de efeitos de estimulações nervosas vistas nas mudanças instantâneas, o contato com o efêmero, fazendo pensar as transformações promovidas por essa modernidade que reflete no crescimento das cidades. 
Outro intelectual que merecemos destacar é Walter Benjamin, que também pensou sobre a modernidade inserida no contexto das transformações do espaço urbano nos séculos XIX e XX. O seu estudo promove a discussão sobre as transformações de Paris na segunda metade do século XIX vista, sobretudo, nos poemas de Baudelaire e na prosa de Balzac. Traço vislumbrado no seu livro intitulado "Charles Baudelaire, Um lírico no Auge do Capitalismo". Partindo do contexto de cultura e modernidade visto no século XIX, Benjamin pôde observar as formas de construção da realidade dos homens, fetichismo da mercadoria, elementos do capitalismo em construção. Destacou desse modo o impacto provocado na vida das pessoas ao se depararem com o turbilhão das grandes cidades, articulando-o às relações capitalistas, ao vislumbre das mercadorias e das tecnologias.

O que significou efetivamente o turbilhão da modernidade? De acordo com Berman (1986) que pesquisou os impactos e modificações que surgiram com a vida moderna, é fundamental entender que se trata justamente de um momento de novas descobertas cientificas, desenvolvimento tecnológico, inovações técnicas, com uma nova definição da concepção de espaço urbano. O autor nos chama atenção para a forma brusca como a vida moderna é definida: uma via de mão dupla, onde muitos se sentem atraídos, enquanto outros são arrastados pela avalanche de modificações.

Neste contexto, os relatos de cronistas e intelectuais é de grande valia quando pensamos as configurações da cidade moderna, nos ajudando a compreender os desejos de modificação da paisagem urbana, a sua veloz transformação, criando assim espaços de memória os quais proporcionam as sensibilidades construídas nessa nova realidade social e visual das cidades.

Não há como negar que as percepções que letrados e intelectuais tinham sobre a cidade e seus moradores eram caudatárias de novas formas de conceber e perceber o mundo, apontando, como sugere Stella Brescianni, para o surgimento de um novo olhar ou de novas sensibilidades.[...] Tais percepções, marcadas por encanto e medo, vão ser abundantemente expressas por médicos, bacharéis, administradores, literatos, etc. (SOUSA, 2003)

Com forte ideário de vida civilizada e progressista, tal elemento norteará não só as grandes capitais europeias, mas também será um fator presente no Brasil, assim a paisagem urbana começa a se modificar adquirindo características que a transforme em cidade moderna, seguindo os parâmetros em voga. As cidades de 
Londres e Paris acabaram por servir de referencial no processo de modernização do Brasil, que de uma maneira ou de outra buscou se enquadrar nos moldes das grandes metrópoles europeias.

O impacto causado nas pessoas ao se depararem com o "turbilhão" das metrópoles foi extremamente ambíguo. Ao mesmo tempo em que este atraía a população encantada por uma série de aparatos que compunham uma cidade considerada moderna, ela assustava e até mesmo aterrorizava. Era algo novo e tudo que é novo é difícil de ser assimilado instantaneamente. De fato, se constituía uma maré forte que conduzia, muitas vezes, os homens contra sua vontade assim como os que gostavam e se envolviam neste inebriante percurso.

É fundamental ressaltar as singularidades da experiência europeia em relação à brasileira, considerando seus limites físicos e sua vivência histórica. A aristocracia colonial brasileira progressivamente vai adquirindo características de uma burguesia industrial preocupada com o capitalismo voltado para o sistema de fábrica que começa a ganhar força no início do século XX. A sociedade brasileira recepciona um processo de transformações sociais, econômicas e políticas, que lhe permitem acompanhar o ideário de progresso e modernização.

Os ventos do progresso soprariam em direção ao Terceiro Mundo e seriam filtrados segundo os olhos e os interesses de suas elites, da mesma forma como os ideais burgueses eram alardeados ao mundo segundo as necessidades do capital triunfante. (PESAVENTO, 1997)

Desta maneira, o Brasil compreendia as mudanças assistidas na Europa, entendendo assim os elementos que também proporcionaram crescimento econômico, com a implantação de fábricas com investimentos do capital estrangeiro que aplicariam as experiências estrangeiras no país, bem como a introdução de novos inventos que facilitaram o cotidiano de uma rica burguesia.

O capitalismo na sua fase monopolista nos tem muito a dizer, sobre a implantação de determinados aparatos modernos. Neste sentido, as sociedades capitalistas europeias se viram na incumbência de expandir a sua acumulação de capital, com o argumento de "civilização" e "progresso", levando assim aos quatro cantos do mundo, as suas tecnologias, máquinas, "maquinarias do conforto" 2 ,

\footnotetext{
${ }^{2}$ Tomar a energia elétrica enquanto equipamento urbano que remete à ideia de conforto para a vida doméstica, tema o qual pertence as reflexões empreendidas por François Béguin que trata do pioneirismo inglês na adoção de certas "maquinarias do conforto". Ver:
} 
tornando-se elementos atraentes para os investimentos industriais. Com isto, o telégrafo, cinematógrafo, eletricidade, linhas férreas se caracterizaram enquanto modificações e benefícios para o cotidiano de uma sociedade dita moderna.

A importância atribuída à eletricidade como uma moderna fonte de energia, faz parte do cenário das grandes exposições universais, espaços dedicados ao exibicionismo burguês com produtos e mercadorias, que traziam todo o otimismo e encantamento progressista que os meios capitalistas poderiam proporcionar. Assim, a dimensão que ganhava as exposições universais perpassava o imaginário dos homens dos séculos XIX e XX. A eletricidade era apresentada como sendo um dos caminhos atrativos para o progresso econômico, adquirindo assim no ramo industrial crescente expansão.

A eletricidade nas exposições universais sempre estava acompanhada de uma série de novas tecnologias, como foi o caso da exposição de 1867 sediada em Paris. No entanto, as possibilidades de utilização da eletricidade como elemento de conforto associado aos grandes investimentos econômicos, fizeram com que os expositores dedicassem-Ihe uma maior atenção. Assim, em 1881, é realizada em Paris a primeira Exposição Internacional dedicada exclusivamente aos profissionais da eletricidade. O brilho da tecnologia da eletricidade a cada evento ganhava mais destaque, apresentando a sociedade burguesa os grandes avanços da luz.

A Exposição de 1900 correspondeu ao auge da descoberta das "seduções da luz", não podendo estar de fora do rol das exposições mais notáveis. O objetivo primordial dos expositores era lançar mão de um evento com amplas dimensões: desejavam, sobretudo, marcar o evento, tornando-o memorável para as décadas posteriores, sendo uma marca registrada. É neste sentido, que temos a criação da estação elétrica de Thomas Edison, que trouxe efeitos que puderam despertar em muito as sensibilidades dos homens que fizeram parte do evento de 1900.

Os visitantes da Exposição de 1900 apreciaram um modelo de estação elétrica arrojado de ferro e vidro. A criação era projetada para as áreas centrais de uma cidade grande, sendo também utilizada para a iluminação em vários espaços dedicados à exposição naquele ano. Este invento objetivava, sobretudo, trazer para os visitantes o contato direto com esta estação elétrica, efetivamente dotada de Estudos Regionais e Urbanos, n 34. São Paulo: ano XI, 1991. 
agilidade de um fio metálico no qual passava uma corrente de voltagens consideráveis que, de acordo com relatos de contemporâneos, era de aproximadamente 100 volts; no pavilhão que expunha a estação elétrica era possível ser visto ao longe, tendo no topo da chaminé uma grande lâmpada elétrica.

A luz artificial moderna mudou consideravelmente os hábitos na esfera do espaço público e privado, elaborando uma nova dinâmica da vida social. Na metade do século XIX tivemos a presença de uma forte intervenção política no que diz respeito à moradia. O objetivo residia na feitura de programas arquitetônicos, os quais estivessem dentro de um projeto mais amplo de urbanizar e embelezar as ruas, assim também a casa deveria passar pelas normas impostas pelos médicossanitaristas e engenheiros, estes dedicavam seus estudos a constante preocupação de manter as casas salubres e higienizadas, partindo da execução de normas e técnicas. Neste período veremos o apelo constante da burguesia em construir uma moradia agradável que proporcionasse um repouso satisfatório, fora das fábricas e do burburinho das ruas.

Diante disso, Béguin (1991, p. 41-44) nos fala da nova dinâmica da salubridade que se construía em práticas e utensílios que fossem capazes de promover a facilidade da vida cotidiana. Tornando-se assim uma novidade que se impôs de forma latente na sociedade burguesa, construindo, mais um meio de acompanhar as modificações em que as cidades ditas modernas deveriam seguir.

Com isto, a arquitetura da casa também se fazia através das suas funções práticas, como, por exemplo, a adoção de determinados aparelhos modernos que viriam a facilitar o cotidiano, a saber: água salubre e canalizada, casa limpa, aquecimento, energia elétrica, entre outros. Uma casa deveria ser limpa e iluminada para facilitar o processo de areação do ar onde poderia circular de forma satisfatória os fluidos.

Somando-se a isto, podemos citar que a existência de um cômodo bem iluminado era positivo para a saúde do morador da casa, assim como a iluminação poderia permitir, entre outras coisas, a ocupação nos mais variados afazeres; facilitaria a leitura de um livro, a atividade de fiar e tricotar, dependendo assim, do que fosse mais aprazível aos moradores do lar.

Neste cenário, é possível verificar todo um conjunto de elementos os quais eram considerados como úteis à vida doméstica, entre eles encontramos a 
utilização da eletricidade, componente do que Béguin chama de "função climática da arquitetura", sendo: a ventilação mecânica, a iluminação elétrica, a climatização.

Verificamos assim a crescente adoção da distribuição da eletricidade para fazer funcionar o rádio, a televisão, o telefone, a geladeira, aparelhos industriais, aparatos tanto de utilidade do espaço público como também para o privado, voltados para satisfazer as necessidades e os desejos que passaram a existir a partir da vida moderna.

Martins (2008) destaca a dimensão que ganha à imprensa nos séculos XIX e XX, momento de grandes modificações vistas nas cidades brasileiras. Por meio dos jornais a sociedade se via sintonizada com as mudanças promovidas pelo capitalismo em construção, a remodelação da paisagem urbana e as novidades que aos poucos entravam nas cidades brasileiras vindas do estrangeiro. As representações construídas pelos intelectuais que escreviam suas matérias nos jornais alicerçavam no imaginário social grandes efeitos na efetivação nos ideários de modernidade.

Sousa (2002, p. 281) nos fala das impressões acerca da recepção dos novos olhares sobre a cidade que são perceptíveis nas páginas dos jornais, que buscaram difundir projetos e ideias em se tratando da modernização. Pautados de denúncias e reivindicações junto aos administradores e o público, fizeram falar dos melhoramentos modernos empreendidos na cidade.

Quem pesquisa com jornais e revistas trabalha com o que se tornou notícia, o que por si só já abarca um espectro de questões, pois será preciso dar conta das motivações que levaram à decisão de dar publicidade a alguma coisa. Entretanto, ter sido publicado implica atentar para o destaque conferido ao acontecimento. (LUCA, 2010, p. 140). Partindo deste pressuposto, nosso olhar sobre as fontes nos permite ir mais além do que um termo a mais para dar intensidade ao fato; elaboramos assim a reflexão do que significaria a utilização sintomática de palavras vistas em nossas fontes de pesquisa as quais recorrentemente apelam em tom dramático, melhorias no que diz respeito ao fornecimento de luz para a cidade.

Ainda em referência ao nosso debate sobre o olhar mais detido em nossas fontes de pesquisas, podemos recuperar as considerações de Aranha (2001, 51, p.53) quando trata de como a adoção de determinados aparatos modernos, a 
saber, as estradas de ferro, que referenciavam a tão falada chegada do trem. Nesse sentido, os elementos modernos surtiram efeitos dos mais variados quando se pensava na cidade adquirir este ou aquele melhoramento, traduzidos muitas vezes, em sonho coletivo e grande desejo de novo.

Desta forma, ao pensar sobre as estradas de ferro e sua repercussão nos jornais da época nos deixa a contribuição metodológica:

[...] O pesquisador não pode deixar se levar pela linguagem própria da época, com seus tons empolados, grandiloqüentes, dramáticos. Trata-se de provocar efeitos, e os letrados de então sabem carregar nas tintas para chamar atenção. Tudo não passa de jogo verbal para atingir o impacto desejado, uma encenação comum por ocasião dos embates em torno de um objeto disputado quanto uma estrada de ferro.(ARANHA, 2001)

Sendo assim, as considerações acima clarificam a necessidade de discernimento do pesquisador ao se deparar com uma linguagem dramática como pode ser vista em nosso trabalho. É importante perceber seus objetivos, argumentos, que visavam, sobretudo, mobilizar uma elite que queria a todo custo mostrar como a cidade de Campina Grande necessitava de uma iluminação elétrica de qualidade. Buscaremos assim apreender os significados impressos nos editoriais, crônicas e matérias afins.

Nosso referencial ao estudar o processo de modernização vislumbrado na cidade de Campina Grande parte das considerações teóricas de Aranha (2003, p. 81-82), o qual estuda a modernidade nas cidades nortistas não com os traços que compõem o quadro das grandes metrópoles caracterizadas pela correria e ritmos frenéticos próprios de uma cidade moderna, mas buscando considerar seu limite físico e, a partir deste, encontrar subsídios para caracterizá-la como tal.

Desde modo, o autor em questão, ao considerar os limites encontrados na região nortista, pensa a cidade moderna por meio de determinadas conquistas materiais. Nosso interesse é fazer uma abordagem que privilegia a energia elétrica entrando na vida das pessoas como uma novidade oriunda do estrangeiro. Queremos pensar o deslumbramento causado na população campinense ao se deparar com um aparato que poderia ser encontrado em uma Londres ou Paris, assim como nas grandes cidades brasileiras.

A ausência de luz elétrica de qualidade em Campina Grande nas décadas de 1920 e 1940 causou na sociedade impressões das mais diversas. As representações construídas em torno da constante oscilação da iluminação podem ser vistas nas URBANA, V.5, no 7, out.2013 - Dossiê: Urbanistas e Urbanismo: a escrita da história... - CIEC/UNICAMP 
páginas dos jornais, como também acabou por refletir nos discursos elaborados pela elite desejosa de progresso.

Devemos pensar a modernidade trazendo como elemento primordial o desejo do novo que se faz presente, o qual não pode ser absolvido instantaneamente, onde percebemos uma assimilação paulatina. Tudo que é novo surpreende, assusta, traz impactos, cria novas sensibilidades sobre a cidade.

Através da leitura da historiografia paraibana quando trata do processo de modernização urbana, fica evidente uma forte preocupação por parte dos gestores e intelectuais empreendidos nas modificações impostas pelo novo cenário da cidade, mais precisamente, a sua crescente modernização. O objetivo era mudar radicalmente aspectos os quais representassem o atraso; desejavam, sobretudo, ampliar suas reformas construindo um novo olhar sobre a cidade, seguindo à risca a esteira de outras cidades brasileiras.

A partir daí, se deve a importância atribuída à iluminação elétrica, a mesma atestava o progresso e civilização. Uma cidade para ser considerada efetivamente moderna deveria possuir elementos que a caracterizassem como tal, logo a ausência deste melhoramento ou sua ineficiência ficava perceptível uma lacuna que impedia atingir o progresso tão desejado.

Recuperando Aranha (2003, p. 122) no caso europeu o grau de civilização de determinadas cidades era mensurado através da quantidade de gás consumido. Embora não tratemos da iluminação a gás, é importante lembrar que esta na sua gênese foi tida como um moderno sistema de iluminação antecedendo a luz elétrica que veio suplantá-lo. O que queremos enfatizar é justamente a importância atribuída à iluminação no contexto de modernização, seja em grandes capitais europeias, seja no caso do Brasil.

Notadamente a implantação da luz elétrica promove como consequência um novo olhar sobre a cidade e seus hábitos noturnos. O trabalho nas indústrias, 0 comércio, as docerias, teatros, cinemas requerem a utilização dessa nova fonte de luz artificial moderna, construindo assim uma tênue distância entre os ritmos do dia e da noite. A vida social ganha outra dimensões assim como a vida privada, traços ligados ao conforto, ao crescimento populacional, à modernização.

A eletricidade desta forma surge como elemento de segurança, tendo em 
vista que as ruas imersas na escuridão contribuíam para a ação dos criminosos, assim como atos de vandalismos praticados por boêmios que atravessam o perímetro urbano após seus divertimentos noturnos. Aumentava as jornadas de trabalho, na medida em que a luz elétrica se tornava maquinaria do prolongamento do dia, servindo à lógica capitalista; e, mais ainda, às possibilidades de diversão noturna: passeios em bares, praças, cinemas.

Tratar da experiência da luz elétrica na Paraíba nos remete a um processo lento e gradual, visto que diferentemente de outras capitais da região Nordeste como Fortaleza e Recife, esta não passou pela intermediação do sistema de iluminação a gás, mas diretamente da queima de querosene para a energia elétrica. A queima do querosene se configurava enquanto um sistema precário e atrasado quando se falava em iluminação pública, principalmente entre as cidades que almejavam se estabelecer nos parâmetros da modernidade ao respirarem ares de progresso. Para compreender o processo de efetivação da energia elétrica e seus efeitos em Campina Grande iremos nos valer em grande medida das matérias jornalísticas e relatos de cronistas e intelectuais que construíram suas impressões mais marcantes acerca deste melhoramento.

Desta forma, ao tratarmos da implantação da energia elétrica na Paraíba é possível verificar, através das fontes documentais e da historiografia da região, as dificuldades de instalação e manutenção, considerando ainda a falta de verbas, onde a iluminação a base de óleo de mamona e de peixe, querosene, por muito tempo, fizera parte do cotidiano paraibano.

Paes (1994), engenheiro elétrico que se dedicou a pesquisa histórica, nos traz em seu estudo elementos que proporcionaram a implantação, fornecimento e manutenção da luz elétrica na Paraíba. Embora se trate de uma obra encomendada, em comemoração aos 30 anos da instituição Sociedade Anônima de Eletrificação da Paraíba (Saelpa), nos ajuda a compreender os aspectos técnicos e administrativos da iluminação na Paraíba.

Neste contexto, as formas de iluminação na Paraíba antes da implantação da energia elétrica se caracterizaram pela utilização de lampiões acionados a azeite de mamona e peixe, acetileno, álcool, querosene. Iluminação precária por atender algumas artérias da cidade, estando presente nas residências de famílias de maior poder aquisitivo, em estabelecimentos e dias festivos. O autor enfatiza a necessidade da capital paraibana no início do século XX possuir como forma de iluminação a eletricidade, tendo em vista que outras regiões do Brasil já sentiam os 
efeitos proporcionados pela energia elétrica, não precisando ir muito longe, podendo citar, por exemplo, o caso de Itabaiana que em 1912, seis dias antes da capital já contava com melhoramento da luz elétrica. Paes informa ainda a dificuldade de implantação do sistema na capital, Parayba do Norte. Os contratos efetivados pelos decretos 288 de 15/02/1906 e 289 de 17/02/1906 não foram cumpridos o que motivou em grande medida o gestor da época, Walfredo Leal a buscar outras concessionárias que tivessem interesse em aplicar seus investimentos elétricos na Paraíba. Desta forma apenas em 1910 é assinado um novo contrato com a empresa Tração, Luz e Força, sendo efetivamente inaugurada em 1912.

A partir da década de 1910, com a chegada do trem na cidade de Campina Grande o cenário se define na busca da implantação da luz elétrica. A historiografia campinense na figura de Epaminondas Câmara em seu livro "Datas Campinenses", anuncia as impressões do progresso econômico e industrial em Campina Grande.

Em 1917, no orçamento estadual recuperado por Câmara $\left(1998\right.$, p. 87-88) ${ }^{3}$, a cidade se destacava na tabela especial de "indústria e profissão" ${ }^{4}$ ganhando espaço entre as cidades paraibanas. Para o cronista a estrada de ferro fez crescer em grande medida o comércio da região, convergindo inúmeros comerciantes, tropeiros, boiadeiros. É justamente com a chegada da ferrovia que Campina Grande passa a viver certa estabilidade econômica e a crescente efetivação das mais variadas atividades voltadas para o comércio e a indústria.

Epaminondas Câmara ainda nos fala do aumento da aquisição de equipamentos e melhoramentos modernos o que contribuiu para dar o tom a uma cidade que passou a ser tão importante como foi a caso de Campina Grande, na Paraíba. No auge, atribuído à indústria capitalista, Campina Grande dedicava tais empreendimentos a Cristiano Lauritzen e Epitácio Pessoa que a agraciaram com a estrada de ferro, possibilitando o desenvolvimento da cidade.

Aos poucos, com a consolidação do comércio, os hábitos tradicionais vão dando espaço para a modernização, os caminhões substituem as carroças de burros, e os postes de energia elétrica dão vida à cidade até então iluminada a

\footnotetext{
${ }^{3}$ A $1{ }^{\circ}$ Edição da obra data do ano de 1947, entendendo assim Epaminondas Câmara como sendo contemporâneo desses eventos.

${ }^{4} \mathrm{~A}$ tabela especial de indústria e profissão fazia referência aos tributos do Estado da Paraíba, onde Campina Grande obteve naquele ano considerável destaque em seu comércio
} 
querosene. $^{5}$

Campina Grande foi agraciada com a luz elétrica no ano de $1920^{6}$, momento este um tanto quanto tardio pelo fato da cidade ser considerada populosa e centro de convergência de comerciantes. As tentativas de implantação da energia elétrica em Campina Grande remontava ao ano de 1915, cujo discurso modernizante já estava bastante aflorado na Paraíba. Desse modo, sob administração de Cristiano Lauritzen, tentou-se a implantação dos serviços de energia elétrica; uma vez que os editais lançados as empresas concorrentes de serviços elétricos não as atraiam a fornecer energia elétrica à cidade, e mais ainda, os contratos em muitas vezes não se efetivavam por conta das divergências entre a empresa fornecedora de energia elétrica e a municipalidade.

Recuperando as considerações de Sousa (2003, p.140-141) a problemática em torno da precariedade da luz elétrica em Campina Grande se deu desde o dia de sua inauguração. Variadas são às vezes em que cronistas, população e elite dirigente se viam prejudicados em relação à luz da cidade.

Em 1924, quatro anos após a inauguração deste melhoramento, o jornal Gazeta do Sertão publica uma notícia informando a necessidade de renovações no contrato quanto ao horário de funcionamento da luz na cidade, elemento este que dificultava as relações comerciais nela realizadas. Vejamos:

A cidade de Campina Grande que é hoje o maior emporio commercial do Estado, está a carecer de luz e força para a garantia de seu comercio. Expliquemo-nos. O contracto do município com a Empreza de luz aqui estabelecida, e somente para fornecer luz á cidade até 2 horas da manhã [...](Gazeta do Sertão- 10/05/1924, ano: XXXVI n²0)

A matéria jornalística referenda a compreensão de que a luz fornecida não mais atendia as exigências do comércio que necessitava de um prolongamento de luz no seu fornecimento, haja vista a ação de "gatunos" durante a madrugada, que invadiam os prédios comerciais trazendo prejuízos aos comerciantes campinenses que pagavam o serviço e não viam retorno deste benefício cotidiano.

\footnotetext{
${ }^{5}$ É importante frisar que mesmo com a implantação da energia elétrica em 1920, ainda existiam casos isolados de ruas e residências que utilizavam outras formas de iluminação

${ }^{6}$ O contrato firmado em 1920 entre o município e a empresa J. Brito \& CIA de Recife (posteriormente Luz e Força S.A), iluminava as principais artérias da cidade, com lâmpadas de 200, 100 e 50 volts, ligadas a um motor Otto de 100 H.P
} 
E o que seria não ter esse serviço ou ser ele precário? A elite campinense fazia intensas denúncias, demonstrando uma preocupação quanto a imagem vislumbrada por aqueles que iam a passeio ou até mesmo visando comercializar na região e a própria sociedade que exigia dos poderes públicos a luz elétrica de qualidade.

Como forma de justificar a necessidade de uma luz de qualidade que pudesse atender maior parte das ruas da cidade, a voz da elite associava à falta de luz a ação da criminalidade consequentemente a crescente ausência

de segurança, e mais ainda ao comércio que também se via prejudicado por não poder prolongar as jornadas do dia no período da noite.

Já na década de 30, por deficiência dos motores, a energia elétrica é diminuída, sendo verificável uma irregularidade no seu fornecimento; nos últimos meses do ano de 1931 a luz desapareceu da cidade; uma iluminação pública que havia sido inaugurada na década anterior já convivia com sua inutilidade. Vez por outra, eram feitos reparos nos motores, mas a deficiência não era suprida efetivamente.

A deficiência de motores não foi um elemento apenas visto no fornecimento de energia elétrica em Campina Grande. Para tomarmos um exemplo mais próximo, percorremos as impressões sobre a experiência da capital paraibana que, desde o início de sua efetivação em 1912, fora penalizada com a prestação de um serviço ineficiente e precário; as razões para tanto residem justamente nos poucos investimentos feitos nos equipamentos elétricos, na falta de engenheiros que fossem responsáveis pela manutenção, e mais o fato de a iluminação atender apenas às principais artérias da cidade.

A cidade de Campina Grande crescia consideravelmente enquanto os motores acabavam por se tornar insuficientes para atender à demanda crescente por mais energia elétrica: diante do alargamento da cidade: uma preocupação não apenas vista nas ruas, mas também nas casas daqueles que podiam pagar pelo serviço de iluminação, que o julgavam caro não valendo a pena pagá-lo.

Consequentemente, por ser um sistema que utilizava máquinas complexas e caras exigiam uma vultosa manutenção. As máquinas muitas vezes vinham da Alemanha e Suécia, levando assim um tempo considerável para chegar a Recife devido à morosidade do trajeto, para só assim serem enviadas à Paraíba. 
A luz muitas vezes era falha devido às medidas empreendidas pelos governantes que para reduzir custos, reduziram também o número de lâmpadas ou privilegiavam determinados espaços, principalmente os frequentados por um grande público em Campina Grande. Um exemplo da redução da luz com o intuito da contenção de gastos data do ano de 1935, quando, mais uma vez, o prefeito Pereira Diniz manda retirar cerca de metade das lâmpadas da cidade, gerando grande indignação por parte da população, haja vista que neste período Campina Grande vivia um momento de grande expansão econômica, tornando-se um centro de comércio algodoeiro de destaque considerável no Brasil. (SOUSA, 2003, p. 140-143).

Neste contexto, iniciamos o debate com Cristino Pimentel e suas crônicas que nos permitem pensar sobre o período em que as ideias de modernização e progresso se cristalizavam na mentalidade da elite campinense: representam reivindicações para o meio urbano, com ênfase no fornecimento de água tratada, esgotamento sanitário e limpeza das ruas; destacam também a iluminação da cidade. Sua crônica expressa a angústia da elite diante da falta de serviços por parte das instituições governamentais nas melhorias de uma cidade considerada tão importante como era o caso de Campina Grande.

Sansonados vão brotando, os frutos da medida tomada, a titulo precario,
pelo Dr. Pereira Diniz, contra a iluminação da cidade. As pombas negras
do pavor já estão acercando dos habitantes da Rua Boa Vista [...]. Trata-
se de arrancar um bando humilde de humanos das malhas rijas da
escuridão que, receioso das causas que costumam se acoitarem no
manto garaúna da natureza pedira ao Snr. Prefeito um pouco de luz
[...](PIMENTEL, Cristino. "Coisas da Cidade", Jornal Praça de Campina,
pp. 2 n $\left.^{\circ} 4-21 / 10 / 1934.\right)$

Assim, percebemos as incisivas críticas que foram feitas à gestão de Pereira Diniz (1934-1935) em relação à iluminação na cidade. Os jornais "A Praça de Campina", "A Batalha", "A Frente" e "Voz da Borborema"7 são fontes valiosas para

\footnotetext{
${ }^{7}$ Praça de Campina: Jornal governista, dirigido por Raimundo Viana de Macedo e Lino Gomes Filho, editado em 30 de setembro de 1934. A Batalha: Jornal diário, iniciando sua circulação em 20 de setembro de 1934. Dirigido por Arlindo Correia da Silva, intitulado enquanto "líder comunista local" da cidade de Campina Grande. A Frente: Primeiro número do jornal publicado em maio de 1934, seguindo a mesma orientação dita "comunista", mantida por alguns sindicatos. Voz da Borborema: sua primeira edição datada inicialmente no mês de julho de 1937 a 1940. Na direção de Acácio Figuerêdo. Publicado bi-semanalmente, as quartas e sábados.
} 
a compreensão de como foram tecidas as querelas em torno da ineficiência da iluminação na década de 30 em Campina Grande.

O prefeito Diniz esforçou-se para sanar a dívida contraída pelo município à empresa de luz, segundo ele contraída por gestores anteriores. A falta de luz se constituía num retrocesso diante da importância da cidade no quadro comercial do Estado. Quando adquiria um novo motor gerador de energia ou alterações no contrato entre a empresa responsável pelo fornecimento da iluminação pública e a prefeitura, logo ficava estampado nas páginas dos jornais que o problema da luz havia sido solucionado.

A cidade foi surpreendida com um magnífico ato administrativo do Dr. Pereira Diniz, que acaba de pagar o debito da Empreza de Luz, herdado de seus antecessores. Nós que já tivemos ocasião de discordar s.s; sentimo-nos a vontade em aplaudir este gesto que o recomenda à estima publica. (Jornal A Batalha "Estabilizando a situação financeira do município" 05/12/1934)

Pereira Diniz ficava isento da "culpa" da falta do fornecimento satisfatório de energia elétrica responsabilizando os prefeitos anteriores por não cumprirem o acordo selado nos contratos entre a empresa Luz e Força S.A e a prefeitura de Campina, assim quando o prefeito assume a gestão da cidade, busca amortizar a dívida.

Tais episódios reforçam a ideia de que para manter a nova fonte de energia não bastava puramente a sua implantação, mas, sobretudo, um conjunto de ações que implicassem o seu desenvolvimento: investimentos em equipamentos, conservação, distribuição e fornecimento da energia elétrica.

Ao indiciarmos os jornais, verificamos que uma das razões para a precariedade do fornecimento era atribuída a certo "tráfico de influências" para a iluminação de determinados estabelecimentos comerciais. Traço dessa medida residia na seletividade de privilegiar alguns espaços em detrimento de outros. Pois,

Ha certos abusos inqualificaveis. Esse, por exemplo, de se deixar varios quarteirões da cidade ás escuras porque um propagandista contrata a energia de que dispõe a nossa inefavel empreza de luz para a iluminação da frente de seus estabelecimento e suas adjacências. Ha quatro dias que as ruas Irenêu Jofilly, João da Mata, Afonso Campos, dr. João Tavares, 13 de Maio, etc., etc., estão literalmente imersas na escuridão. Reclamações e mais reclamações nos estão chegando dos diversos habitantes desta cidade, imensamente prejudicados com essa "absorção" 
da luz publica e particular com a anuência reprovavel de uma empreza cuja deselegancia e desidia ao mais comesinho preceito contratual roça pela extravagancia.

Segundo estamos informados as pessôas que vêm sendo prejudicadas com esse inominável monopolio da luz campinense vão dirigir-se ao prefeito Bento Figueiredo, a fim de exorar do chefe do executivo municipal as necessarias providencias. (Voz da Borborema. "Continúa a escuridão". 15/10/1939)

É importante compreender que a falta de luz em Campina Grande se torna tão recorrente que ao recuperarmos mais uma crônica de Cristino Pimentel verificamos a banalização do caso, na medida em que, ao tratar de outras questões relacionadas ao aspecto de organização do espaço urbano e seu embelezamento, faz uma crítica contundente ao fornecimento de luz na cidade, como se não fosse mais surpresa de deparar com o constante oscilar de luz.

[...] Um sol muito aberto ajuda a pupila, embora que ela só se dilate mais á noite para, como os gatos, vêr melhor. Digo que ajuda a pupila porque põe a descoberto um sujo posto no canto ou uma nodoa que a noite encubra. Isto ninguem discute porque se sabe qual o destino da noite especialmente em Campina Grande, que a illuminação em vez de" aparecer aos olhos da noite", se assemelha a um rosário de mandingas no pescoço de uma feiticeira. (PIMENTEL, Cristino. Coisas da Cidade. Voz da Borborema, 05/02/1938)

A partir da crônica de Cristino Pimentel podemos recuperar as representações construídas em torno da "fada elétrica" ${ }^{8}$ que surge nas Exposições Universais como sendo capaz de milagres modernos por suas transformações técnicas construídas pela sociedade industrial. A simbologia remete a fada que com apenas um toque da sua "varinha de condão" era capaz de fazer uma lâmpada elétrica funcionar, vinda do céu para construir toda a magia da tecnologia da eletricidade. A eletricidade foi considerada pelos contemporâneos dos séculos XIX e XX a "grande fada" que espalhou o maravilhoso e o prodígio por toda a Exposição de 1889 e 1900, seus efeitos eram vistos como verdadeiros

\footnotetext{
${ }^{8}$ Sobre essa expressão "fada eletricidade" é possível recorrer a: BARBUY, Heloisa. A exposição Universal de 1889 em Paris. Programa de pós-graduação em História Social da USP. Edições Loyola. São Paulo, 1999; GUERREIRO, António. Exposições Universais Paris 1900. Edição: Expo Lisboa 98. Lisboa, 1995 e CENTRO de Memória da Eletricidade no Brasil. A vida cotidiana no Brasil moderno: a energia elétrica e a sociedade brasileira (1880-1930). Rio de Janeiro: Centro de Memória da Eletricidade no Brasil, 2001.
} 
milagres mecânicos que se confundiam entre o sonho e a realidade, trazendo assim todo o poder do fenômeno elétrico.

Por conta da cidade de Campina Grande conviver com as constantes oscilações de sua lluminação acabava por associar, pejorativa e preconceituosamente, aos malefícios atribuídos as feiticeiras. Assim, a iluminação da cidade era vista como um "rosário de mandingas no pescoço de uma feiticeira", algo visto em seu aspecto mais negativo, seguindo o qual o mal se caracterizava pela carência de luz.

Devemos lembrar ainda do desejo desses letrados de ver a cidade apresentada aos seus habitantes e visitantes com ar de "progresso" e "civilização", e se por algum motivo "algumas tochas" davam a "impressão de uma cidade decadente", ela não podia acompanhar o ritmo de algumas cidades em franca civilidade, uma preocupação notável nos discursos da elite. Campina Grande por ser composta de muitos intelectuais e letrados que tinham contato com outras regiões brasileiras as quais viviam considerável expansão no tocante à modernização, se viam na militância de trazer as benesses do "progresso" para a sua cidade.

Diante disso, merecemos destacar um editorial publicado na Voz da Borborema em 18 de junho de 1938, que nos mostra de forma emblemática a caminhada de Campina Grande para atingir o patamar da "civilização".

Como se não bastasse à luz ineficiente, os funcionários que prestavam serviço à empresa Luz e Força S.A, ainda constrangiam os moradores, ao serem submetidos ao serviço mal feito pela empresa de luz.

Nada é mais revoltante, atualmente, em nossa terra, do que o
insolúvel problema da "Luz".
A cidade tem vivido nesses ultimos tempos, numa constante
escuridão. A população já está farta de tanto esperar e confiar nas
infinitas promessas da Empreza.
Numa das ruas desta cidade, em frente ao Grupo Escolar Solon de
Lucena, onde passa uma rêde da iluminação eletrica, os zelosos
funcionarios da Empreza de "Luz", estão aplicando ultimamente os
paralelepípedos no carçamento, que a Prefeitura com zelo e
capricho faz com o mais perfeito acabamento, para o serviço de
esticar as suas redes, afim de não se chocarem os fios uns contra
os outros. Tal situação é lamentavel para uma cidade como
Campina Grande, pois além de não termos luz, a empresa que
assumiu a responsabilidade para dota-la desse melhoramento, cada
vez mais procura humilha-la com semelhantes abusos. E assim,
sempre sem luz e com as pedras do calçamento servindo de
macacos á Empresa, Campina marcha garbosamente para a URBANA, V.5, no 7, out.2013 - Dossiê: Urbanistas e Urbanismo: a escrita da história... CIEC/UNICAMP 
civilização. (ALMEIDA, Possidio R. de. A nova função das pedras do calçamento. Voz da Borborema, 18/06/1938)

Fica evidente que uns dos projetos urbanísticos que objetivavam o nivelamento das ruas, com a crescente transformação de ruas estreitas e labirínticas em ruas largas e aformoseadas faziam parte das reformas urbanas empreendidas pelos gestores de Campina Grande. Nesse contexto, o mau serviço prestado pela companhia que fornecia a luz elétrica ainda atrapalhava outros empreendimentos voltados para a modernização da cidade. O próprio título do editorial nos tem muito a dizer: "A nova função das pedras do calçamento" destacando que além das ruas calçadas e largas, facilitarem a circulação dos comerciantes e automóveis e seu incremento do espaço urbano nas relações cotidianas, ainda servia como paliativo para medidas que visavam o fornecimento de luz, que em grande medida, iam contra a estética e arquitetura do centro da cidade.

O articulista é irônico, na medida em que critica a utilização das pedras para a serventia de macacos a empresa Luz e Força S.A, a cidade caminhava lentamente ao nível de civilização tão desejado.

Retomando as impressões causadas na recepção da luz elétrica e suas implicações nas sensibilidades dos homens campinenses, podemos reproduzir a fala destacada por Cabral Filho (2007, p. 109) através do texto poético do médico Severino Bezerra de Carvalho que rememora suas lembranças acerca da iluminação de Campina Grande.

Oh, a poesia das noites campinenses, com as luzes dos postes (e também das casas) naquele oscilar constante, entre um rosa tênue de brasa quase extinta e a quase azulescência de uma estrela!... Era o malabarismo permanente da voltagem, agora em 80 e logo, logo em 180 volts. Oh, a doçura de passear, a mão na mão da namorada, por aquelas ruas e ruelas, não direi penumbrosas, porém um tanto ou quanto vagalumeantes, ouvindo aqui e acolá um piano machucar um "Pour Elise" ou um trecho de Mozart!...

O médico Severino Bezerra de Carvalho décadas após o acontecimento narrado rememora com romantismo e saudade a sua juventude ao lado se sua amada nas noites campinenses que mesmo com o oscilar constante de luz ainda o trazia boas lembranças, mesmo na sua ausência era possível iluminar 
precariamente "vagalumeantes" as noites dos namorados. As impressões são marcantes, na medida em que, a esperança flui com as emoções do inconsciente do autor. É perceptível a idealização em se tratando dos novos aparatos modernos, onde vislumbramos os limites que perpassam o próprio ideário de modernização.

Consideramos assim, que as emoções fluem e se tornam consistentes quando a elite se depara com situações de medo e de atraso. Os limites refletem a dificuldade se construção da dinâmica da vida social nas suas mais variadas esferas.

A precariedade da iluminação em Campina Grande nos anos seguintes a sua implantação fazia parte das queixas de uma elite que buscava modificar seus hábitos, com o desejo de ver a Rainha da Borborema com seu crescente empório comercial incrementada pela diversão e lazeres noturnos. Uma vida noturna que, segundo relatos da época, estava paralisado, devido ao constante oscilar de luz ou sua ausência completa.

Aqueles que percorriam as ruas e avenidas centrais durante a noite corriam sérios riscos, pois "a cidade tem provocado verdadeiro terror, mergulhada, como está, na temeridade das trevas". 9

O medo era perceptível, reflexo da falta da iluminação pública. Medo associado à violência das ruas marcadas pela escuridão. Desta forma, percebemos nas matérias analisadas, entre crônicas, manchetes e editoriais, muitas vezes intitulados de "o Caso da Luz"10, a presença recorrente do termo "trevas".

Para tanto acreditamos que as trevas significavam na fala da burguesia, um verdadeiro atraso em se tratando de iluminação, comprometendo, consequentemente a cidade "civilizada" e "progressista". Desse modo, as trevas maculavam, na ótica dos letrados, todo o progresso econômico que vivia a cidade. A elite acreditava que os comerciantes que vinham à cidade, poderiam construir uma imagem negativa por perceber a carência de um serviço visto como tão importante empreendimento para as cidades modernas.

\footnotetext{
${ }^{9}$ Voz da Borborema. Campina Grande e a sua Iluminação. 9/4/1939

${ }^{10}$ Semanalmente o Jornal Voz da Borborema trazia informações sobre o desenrolar dos acontecimentos acerca da luz elétrica com o título "O Caso da Luz".

URBANA, V.5, no 7, out.2013 - Dossiê: Urbanistas e Urbanismo: a escrita da história... CIEC/UNICAMP
} 
A população campinense está perdendo a paciencia com a falta de luz. 0 escarneo da Empreza aumenta dia a dia, e não há uma esperança de solução, ao magno problema, por parte da mesma. Não é possível, porem, que uma cidade como Campina Grande, continue mergulhada nas trevas. (Voz da Borborema, 9/04/1938)

O trecho acima vem referendar que as trevas refletiam em grande medida o atraso quando comparado a outras regiões. Não havia mais paciência para esperar medidas, pois já se estava no ano de 1938 e o problema não havia sido solucionado substancialmente. Tornava-se a ordem do dia: reclamar, reivindicar, cujo apelo se fazia uníssono na luta por um fim das trevas, logo, da precariedade do fornecimento de luz.

Até quando reinará a treva em Campina Grande? Não é possível que um centro comercial, da envergadura desta cidade continue imerso na escuridão, e inteiramente a mercê duma empreza que abusa do povo e dos poderes públicos municipais e estaduais.(Voz da Borborema, $18 / 05 / 1938)$

As trevas ainda podem ser vistas como penitência pela qual os campinenses deveriam passar ou até mesmo castigos que estes estivessem a receber. Era importante de fato, suportar; afinal, eram cidadãos inocentes e resignados. Um dia um raio de luz, rasgaria as trevas em que os campinenses viviam. Atentemos para o tom irritado e ao mesmo tempo irônico do jornal Voz da Borborema em um de seus editoriais sobre o "caso da Luz".

Não sabemos mais, de que maneira possamos verberar contra a indesejável iluminação que a Empreza Eletrica S.A. , desta cidade, vem fornecendo, de longa data, á população campinense.

As campanhas acirradas com que o povo, o comercio e os jornais da terra se teem movimentado em justas reclamações e energicos protestos pela falta de bôa luz ao nosso meio, não conseguiram impressionar, ainda, um só instente, os senhores concessonarios da prefalada Empreza, que assistem, a tudo, indiferente e desdenhosamente, prometendo apenas...

O que nos resta a fazer agora?!

Suportamos, sempre... sempre... e pacientementes tão deselegantes tapeações segundo as quais a E.L.F.S.A. vem nos

"enchendo as ventas de fala"!

Isto, não!

[...] Como diziamos, não sabemos como se conseguirá ver, um dia, a bela cidade serrana que é Campina Grande, illuminada de molde a impressionar bem o quantos aqui teem aportado cotidianamente. Está claro, pois, que aos responsáveis pela referida Empreza pouco se lhe da venha ou não a nossa terra resvalar no declínio da decadencia, pela falta 
de iluminação!...(Voz da Borborema. Campina Grande continua irremediavelmente ás escuras. 21/05/1938)

Sublinhamos a preocupação da elite em mudar os rumos da falta de luz na cidade de Campina Grande. Parece-nos que tudo havia sido feito, as esperanças talvez não mais existissem, haja vista a indiferença da empresa de luz responsável por um fornecimento satisfatório. Campina Grande, de acordo com os relatos, ao invés de caminhar para os redutos do progresso, caminhava efetivamente em direção contrária, esta marcada pela decadência, por conta da falta de iluminação. 
Os campinenses poderiam padecer caso quisessem ir ao cinema, pois quando a energia funcionava neste espaço, a luz em outros lugares eram suprimidas no intuito de fornecer uma energia de qualidade razoável para o cinema. "Sucede também que a Empresa, cuja energia não chega para satisfazer á do contrato ainda mantém contrato com o Capitólio de forma que quando funciona... é, brasa na colher na cidade inteira!"11

Mais uma vez, a falta de luz na sua "treva mais densa" era a forma mais comum vista no jornal Voz da Borborema sobre a iluminação na cidade.

Pesar dos esforços empregados por quem de direito, como já noticiamos, no nosso ultimo numero, a cidade continua mergulhada na treva mais densa, com a sua vida noturna completamente paralizada. Estamos sem luz de especie alguma. Têm sido constantes as reclamações. No desempenho da nossa missão, nenhum proposito temos com os fornecedores da luz da cidade, apenas nos fazemos éco das queixas e clamôres do povo campinense, que não pode nem se acostuma a viver numa cidade em completa escuridão."(Voz da Borborema. "A cidade em completa escuridão. 19/10/1938.)

A matéria acima reflete o sentimento de perda. Perda, na medida em que, mesmo com as constantes reivindicações e notícias publicadas diariamente na imprensa, não mudavam os rumos da luz da cidade. Os ritmos e os lazeres noturnos não poderiam ser prolongados até a noite, haja vista que as principais ruas permaneciam na escuridão. Atentamos ainda para o fato de que, mesmo vivendo durante períodos constantes de falta de luz, os campinenses não se acostumavam a viver sem energia elétrica. Era praticamente impossível aproveitar a noite: "As famílias estão se esquivando, e com justa razão de sair ás praças, nos passeios públicos, atemorizados com a escuridão, sob que se vêm imersos todos esses

\footnotetext{
${ }^{11}$ O Rebate. A Empresa De Luz De Campina Grande Continua em Verdadeiro Estado de Imprestabilidade. 16/01/1937.
}

URBANA, V.5, no 7, out.2013 - Dossiê: Urbanistas e Urbanismo: a escrita da história... CIEC/UNICAMP 
recantos das nossas artérias urbanas". ${ }^{12}$

O temor sempre é enfatizado quando se projeta o usufruto noturno da cidade, pois as ruas não possuíam iluminação suficiente. Remete-se a insegurança originado com a oscilação da luz; imagina-se situações de risco, causando malefícios: a vida parecia correr perigo.

A partir daí, podemos compreender como os letrados campinenses recorreram à escuridão para introjetar o medo no inconsciente coletivo. 0 medo, insegurança, atraso eram sentimentos imprescindíveis às representações em torno de uma Campina Grande desejadamente moderna.

Os motores, segundo os depoimentos vistos na imprensa eram "estragados, adquiridos de terceira ou quarta mão, como ferro velho" não sendo capazes de satisfazer as necessidades da cidade. Sem falar da "oscilação incomoda e irritante", e nos momentos que mais se precisava de luz ela faltava completamente.

É mister frisar que as discussões em torno da iluminação da cidade e sua precariedade não foram vistas apenas em praças públicas e na imprensa: ganhou maiores proporções ao torna-se um caso judiciário ainda em 1937. No dia 4 de dezembro de 1937, nas matérias referentes ao caso da luz, foi possível vislumbrar a divulgação de uma nota por parte da prefeitura, que, por meio do advogado Otávio Amorim, executava uma petição pedindo a rescisão do contrato de 1931: entre as cláusulas exigisse melhores motores, um tempo maior de fornecimento de luz, bem como uma voltagem de maior capacidade, lembrando ainda que as ruas mais afastadas careciam de luz.

O contrato de 1931, entre suas cláusulas, exigia que a empresa de luz na ocorrência de deficiência dos aparelhos técnicos e suas máquinas, em tempo hábil, deveria solicitar a aquisição de novas máquinas, cumprindo assim o contrato na medida em que não iria penalizar a sociedade campinense com a falta de luz.

${ }^{12}$ Voz da Borborema. "Campina Grande e a sua iluminação. 09/04/1939. 
Porém, no decorrer dos anos, a empresa não vinha cumprindo as exigências contratuais, a força motriz que em 1931 tinha como meta fornecer 500 H.P, em 1937 fornecia uma quantidade bem inferior a desejada. Entre outras queixas em relação à empresa havia uma que dizia respeito ao horário da iluminação, que não se efetuava na hora estabelecida e quando sim, era uma luz oscilante. Esses motivos apresentados na argumentação do advogado Otávio Amorim faziam a cidade "sofrer graves distúrbios" em vários setores sociais: educação, moradia, lazer, comércio e indústria.

Percebemos claramente o impacto que vai marcar as mudanças vividas nas cidades que começavam a sentir os efeitos da modernização. Neste contexto, juntamente com a preocupação com a construção do sistema de água e esgotos, teremos a precariedade do fornecimento de luz, e seus desdobramentos tocarão não só o campo material, mas também o campo do sensível.

Os anos se passam e a problemática em se tratando da iluminação de Campina Grande ainda pulsa forte nas veias da elite campinense. 0 trecho abaixo clarifica o que se pretende expor:

Algumas tochas espalhadas no perímetro de poucas ruas, como brazas dependuradas, não illuminam coisa alguma e dão à impressão de uma cidade decadente, em contraste a sua real opulência. A nossa cidade as escuras, outro não será o seu desejo senão de nos ver em franca decadência e inferioridade. (Voz da Borborema, 6/04/1938).

O mesmo pode-se apreender de um letrado anônimo que, ao visitar a cidade, admira-a em vários aspectos, porém quando se refere à iluminação pública "O que é de lamentar sobre modo é o serviço da luz em Campina Grande, contrastando com seu gráo de civilização e progresso." 13

Como já anunciamos em outro momento, no intuito de resolver o problema da luz, a voz dos cronistas e jornalistas se tornou um veículo de denúncias. Hortênsio Ribeiro foi um dos tantos letrados que trataram desta questão com veemência.

${ }^{13}$ Voz da Borborema, 29/01/1938.

URBANA, V.5, no 7, out.2013 - Dossiê: Urbanistas e Urbanismo: a escrita da história... CIEC/UNICAMP 
As áreas mais afastadas não eram agraciadas com tal benefício e, vez por outra, as principais ruas dormiam na escuridão, sendo evidente a necessidade de luz fixa e de qualidade, satisfazendo a cidade como um todo. Embora contratos fossem renovados e/ou alterados, a população em pouco tempo já vociferava indignação com a precariedade da iluminação fornecida. Hortênsio Ribeiro clarifica a discussão acerca da iluminação pública ao rememorar o ápice da reforma urbana empreendida por Vergniaud Vanderley ${ }^{14}$, sofrendo sua demasiada inutilidade:

Quando o prefeito Verniaud Wanderlei empreendeu a edificação do Grande-Hotel, ás duas por três lhe observamos, que sem a luz publica campinense afiguravase-nos, monumental e inútil, a gigantesca construção do hotel da cidade. A execução deste melhoramento implicava naturalmente na realização do suprimento de luz á Campina. (RIBEIRO, Hortênsio "Luz Publica de Campina Grande", Voz da Borborema, n॰63, 31/08/1938).

O episódio acima reflete a contradição presente na busca da inserção nos parâmetros das cidades ditas modernas. Enquanto um hotel era edificado dando mais vida ao centro da cidade de Campina, para seu funcionamento de fato necessitava de luz de qualidade, logo configurando a precariedade da iluminação e conseqüentemente um obstáculo para o "melhoramento" da cidade.

As dificuldades em torno do fornecimento de energia elétrica não se encerram com os tramites judiciais, muito pelo contrário, não encontramos soluções ao nos debruçarmos nas fontes estudadas. A escuridão continua. Traço disso pode ser vislumbrado quando se fala que mesmo com novos motores a luz da cidade ainda era falha. A empresa que fornecia a luz da cidade buscava cumprir seus contratos, no entanto, algumas implicações de ordem técnica impediam seu melhor funcionamento. Assim, se tornou corriqueiro a cidade conviver, noite após noite, com a mais total escuridão.

\footnotetext{
${ }^{14}$ Considerado pela historiografia paraibana como o gestor municipal que promoveu verdadeira reforma urbana na cidade, buscando dotá-la de parâmetros modernos em voga na sociedade brasileira. Uma cidade de progresso com saneamento, hotéis de luxo, prédios de mais de um pavimento, água salubre, praças, energia elétrica, dando continuidade à reforma arquitetônica empreendida em anos anteriores, por outros gestores da municipalidade.
} 
O precário fornecimento de luz em Campina Grande fez com que na década de 1940, a municipalidade se preocupasse ainda mais em trazer melhorias para este sistema tão problemático. Afinal, a eletricidade, a cada dia, se tornava elemento fundamental das relações econômicas e sociais da cidade e da própria esfera do conforto.

Desse modo, em 1944 se inicia a construção da nova central elétrica na cidade. Era necessário que o município tomasse medidas efetivas para as melhorias no sistema de eletrificação da cidade. No mesmo ano, a empresa de luz passa à direção do município, e passa a chamar-se "Serviços Elétricos Municipais." Novas tensões, conflitos e desejos estavam a caminho.

\section{Considerações Finais}

Ao enveredarmos pelo estudo da implantação da luz elétrica em Campina Grande foi possível perceber parte dos desejos de uma elite que ansiava por "progresso" e "civilização", traços que refletiam uma vida que se pautava nos discursos modernizantes em voga.

Estamos tratando de um melhoramento que trouxe uma série de modificações nos hábitos e práticas cotidianas. A energia elétrica era promessa de prolongamento das jornadas de trabalho, de fruição de novos espaços de sociabilidade e lazeres noturnos e a utilização de novos equipamentos de uso industrial, comercial e doméstico.

A partir de uma análise atenta das fontes foi possível perceber os limites deste equipamento de conforto na cidade. Várias foram as vezes em que cronistas, jornalistas e políticos trataram do que se chamou à época "o caso da luz", como um símbolo de atraso no que diz respeito à trajetória da cidade nos padrões da modernidade.

Quase duas décadas após a inauguração da iluminação elétrica na cidade de Campina Grande, percebemos o forte apelo e o discurso dramático da elite que buscava uma luz de qualidade para suprir as suas necessidades cotidianas. As matérias jornalísticas apresentadas em forma de editoriais, crônicas, poesias e cartas de seção foram construídas como forma de tornar público a precariedade da luz elétrica em Campina Grande, 
seja no espaço público ou no espaço privado.

Por meio das matérias jornalísticas buscou-se construir o medo no imaginário dos campinenses, uma vez que a falta de luz deixava as ruas da cidade e seus domicílios em plena escuridão. Os jornais procuraram convencer os seus leitores que, com a ausência de luz, a sociedade ficava vulnerável à ação de criminosos; impossibilitada em grande medida de aproveitar a noite, como, por exemplo, ir ao cinema, às praças e aos lazeres que as noites campinenses ofereciam. Neste contexto, não podemos nos esquecer do conforto nos domicílios que também eram prejudicados com o oscilar quase que constante de luz.

Duras críticas foram feitas à empresa de luz da cidade. O discurso modernizante teve que pautar as limitações no que se refere à implantação, fornecimento e manutenção deste equipamento moderno na cidade. Na ótica dos letrados, a Empresa de Luz e Força S.A de Campina Grande se tornava a grande vilã que impedia a Rainha da Borborema de seguir os rumos da tão sonhada modernidade. A indiferença da empresa fornecedora de energia elétrica crescia, na medida em que os anos se passavam, e nada de substancial era feito para um satisfatório fornecimento de luz.

Durante nossa pesquisa podemos perceber o esforço atribuído a algumas figuras políticas que se engajaram por melhorias no sistema de iluminação da cidade de Campina Grande. Podemos citar os prefeitos municipais Pereira Diniz (1934-1935), Vergniaud Wanderley (1936-1938; 1940-1942) e Bento Figueiredo (1938-1940), que foram tornados administradores emblemáticos na busca reiterada por firmar contratos com a empresa de luz para um melhor fornecimento. Assim, percebemos as impressões da elite acerca desses gestores: ora são glorificados por atenderem às expectativas de uma iluminação condizente com a cidade, ora duramente criticados por não atenderem aos apelos contra o insatisfatório fornecimento de energia elétrica.

Os anos se passam e a problemática em torno da precariedade da luz elétrica continuou. As tensões e os conflitos perduraram. A energia elétrica em Campina Grande foi implantada entre altos e baixos: se melhorias eram vistas, em pouco tempo a elite retomava com mais afinco, pois a luz logo se mostrava deficiente e oscilante. 
Tudo isto se configurou como traço de uma cidade que desejava ser progressista e, sobretudo, moderna, elemento este que poderia ser visto na adoção de equipamentos modernos. Este projeto modernizante teve que ser postergado, uma vez que foi somente a partir da segunda metade do século XX que uma parcela considerável da população de Campina Grande passou a usufruir de um fornecimento de energia elétrica que foi se compatibilizando com as suas necessidades materiais e simbólicas.

\section{Referências Bibliográficas}

\section{Fontes:}

Revista Campinense (1920)

O Rebate (1932 e 1937) - Jornais avulsos

A Frente (1934) - Jornais avulsos

A Batalha (1934-35)

Jornal Voz da Borborema (1937- 1939)

\section{Livros e Artigos:}

ARANHA, Gervácio Batista. Trem, modernidade e imaginário na Paraíba e região: Tramas político-econômicas e práticas culturais (18801925) Campinas- SP, Agosto de 2001. Tese de Doutorado.

\section{- Seduções do moderno na Parahyba do Norte:}

trem de ferro, luz elétrica e outras conquistas materiais e simbólicas (18801925).

In: A Paraíba no Império a República: estudos de história social e cultural. João Pessoa: Idéia, 2003.

- Trem e imaginário na Paraíba e região: Tramas

Políticas e Econômicas. Campina Grande: EDUFCG, 2006.

BRESCIANNI, Maria Stella Martins. Londres e Paris no século XIX: o espetáculo da pobreza. 8.ed. São Paulo: Brasiliense, 1994.

História e Historiografia das cidades, um percurso.

In: Historiografia Brasileira em perspectiva. Marcos Cezar de Freitas (org.) Editora Contexto: São Paulo, 1997. 
O literato, o cronista e o urbanista. Imagens de

São Paulo nos anos 1910-1920. In: Escrita, Linguagem, objetos: leituras de história cultural. PESAVENTO, Sandra Jatahy (org.) Bauru, SP : EDUSC, 2004.

BÉGUIN, François. As maquinarias inglesas do conforto. In: Espaço e Debate- Revista de Estudos Regionais e Urbanos, n 34. São Paulo: ano XI, 1991.

CABRAL FILHO, Severino. A cidade através de suas imagens: uma experiência modernizante em Campina Grande (1930-1950) Universidade Federal da Paraíba, UFPB. Doutorado em Sociologia, 2007.

A cidade desejada: Campina Grande, imagens e

história. In: Antonio Clarindo B. Souza; Eugêniz M. Dantas; Iranilson B. de Oliveira; Joel C. S. Andrade. (Org.). Cultura e Cidades. $1^{\text {a }}$ ed. Campina Grande: Editora da Universidade Federal de Campina Grande, 2009, v, p. 40-54.

CÂMARA, Epaminondas. Datas Campinenses. 2॰ed. Campina Grande: Caravelas, 1998.

CENTRO de Memória da Eletricidade no Brasil. A vida cotidiana no Brasil moderno: a energia elétrica e a sociedade brasileira (1880-1930). Rio de Janeiro: Centro de Memória da Eletricidade no Brasil, 2001.

CHARTIER, Roger. A História Cultural: entre práticas e representações. Tradução Maria Manuela Galhardo. Rio de Janeiro: Bertrand Brasil, 1990.

GINZBURG, Carlo. Mitos, emblemas e sinais Morfologia e História. $1^{a}$ reimpressão. São Paulo: Companhia das Letras, 1986.

LUCA, Regina Tânia. Fontes Impressas História dos, nos e por meio dos periódicos. In: Fontes Históricas. São Paulo: Contexto, 2010.

MARTINS, A. L.; LUCA, T. R.. A História da Imprensa no Brasil. São Paulo: Contexto, 2008.

PAES, Marcelo Renato de Cerqueira. Do Azeite de Mamona à Eletricidade Anotações para uma História da Energia Elétrica na Paraíba. 2 ed. João Pessoa: Editora Rivaisa, 1994.

PESAVENTO, Sandra Jatahy. História \& História Cultural. Belo Horizonte: Autêntica, 2003.

RAMINELLI, Ronaldo. História Urbana. In: Domínios da História: Ensaios 
de teoria e metodologia/ Ciro Flamarion Cardoso, Ronaldo Vainfas (orgs.). Rio de Janeiro: Elsevier, 1997.

ROCHA, Amaral Silva de Sousa. A Sedução da luz: eletrificação e imaginário no Rio de Janeiro da belle èpoque (pp.51-80). In: Revista de História Regional, n॰2. Ponta Grossa: Imprensa Universitária da UEPG, 1997.

RONCAYOLO, Marcel. Transfigurações noturnas da cidade: 0 império das luzes artificiais (pp.97-101). Tradução de Eveline Bouteiller Kavakama. In Projeto História. 1999.

SOUSA, Fábio Gutemberg Ramos Bezerra. Cristino Pimentel: Cidade e Civilização em crônicas. In: A Paraíba no Império a República: estudos de história social e cultural. João Pessoa: Idéia, 2003. "Campina Grande: cartografias de uma reforma urbana no Nordeste do Brasil (1930-1945)" (pp. 61-92). In: Revista Brasileira de História, vol.23, n॰ 46. São Paulo: ANPUH, 2003 